Pak. j. sci. ind. res. Ser. B: biol. sci. 201356 (1) 29-35

\title{
High-Performance Liquid Chromatographic Quantification of Rifampicin in Human Plasma: Method for Therapeutic Drug Monitoring
}

\author{
Trabelsi Sameh $^{\text {ab }}$, Eljebari Hanene ${ }^{\mathrm{a} *}$, Charfi Rim ${ }^{\mathrm{ab}}$, Salouage Issam ${ }^{\text {ab }}$, Gaïes Emna $^{\text {ab }}$, \\ Nadia Jebablia Lakhal Mohamed $^{\text {ab }}$ and Klouz Anis ${ }^{a b}$ \\ ${ }^{a}$ Laboratory of Clinical Pharmacology, National Centre of Pharmacovigilance, \\ 9, Avenue Dr. Zouheir Essafi, 1006, Tunis, Tunisia \\ ${ }^{\mathrm{b}}$ Faculty of Medicine, El Manar University, Tunis, Tunisia
}

(received January 11, 2012; revised March 28, 2012; accepted June 11, 2012)

\begin{abstract}
A high performance liquid chromatography (HPLC) method has been developed that allows quantification of Rifampicin in human plasma. The method is based on the precipitation of proteins in human plasma with methanol. Optimal assay conditions were found with a C18 column and a simple mobile phase consisting of $0.05 \mathrm{M}$ dipotassic hydrogen phosphate buffer and acetonitrile $(53 / 47, \mathrm{~V} / \mathrm{V})$ with $0.086 \%$ diethylamin, $\mathrm{pH}=4.46$. The flow-rate was $0.6 \mathrm{~mL} / \mathrm{min}$ and the drug was monitored at $340 \mathrm{~nm}$. Results from the HPLC analyses showed that the assay method is linear in the concentration range of $1-40 \mu \mathrm{g} / \mathrm{mL}\left(\mathrm{r}^{2}>0.99\right)$. The limit of quantification and limit of detection of Rifampicin were $0.632 \mu \mathrm{g} / \mathrm{mL}$ and $0.208 \mu \mathrm{g} / \mathrm{mL}$, respectively. Intraday and interday coefficient of variation and bias were below $10 \%$ for all samples, suggesting good precision and accuracy of the method. Recoveries were greater than $90 \%$ in a plasma sample volume of $100 \mu \mathrm{L}$. The method is being successfully applied to therapeutic drug monitoring of Rifampicin in plasma samples of tuberculosis and staphylococcal infections patients.
\end{abstract}

Keywords: rifampicin, liquid chromatography, therapeutic drug monitoring

\section{Introduction}

Rifampicin (RIF), a semi-synthetic macrocyclic complex antibiotic derived from Streptomyces mediterranei, is member of rifamycin class antibiotics (Maggi et al., 1966) used for the treatment of tuberculosis and other infectious diseases such as staphylococcal infections (Tsankov and Angelova, 2003). It is categorised as one of the first line antituberculous agents; however various side effects such as hepatotoxicity, allergic rashes, lack of appetite and nausea or immunological disturbances have been reported with its administration (Gallieni et al., 1999). The therapeutic drug monitoring (TDM) of RIF is necessary if the cultures are still positive for Mycobacterium after two months of treatment. TDM is important when it is a risk of under dosing, especially (i) in the infection with Mycobacterium avium, and the tuberculosis meningitis (Yew, 1998) (ii) in immune deficiency syndrome patients in which the gastrointestinal absorption of antibacterial drugs is reduced and when the incidence of infection by Mycobacterium avium is increased (Peloquin, 1997) (iii) drug interaction (with imidazole antifungal and/or pyrazinamide). The TDM is also necessary in situations where the risk of

*Author for correspondence; E-mail: eljebarihanene@yahoo.fr toxic accumulation is increased particularly in liver dysfunction and renal failure (Peloquin, 2002; Yew, 1998; Peloquin et al., 1996).

TDM of RIF is also useful in case of serious illness associated with gastrointestinal disease, cystic fibrosis, diabetese and in children regardless of the clinical situations. The variability in RIF's concentration and absorption due to concomitant food supported RIF TDM (Zent and Smith, 1995).

Tuberculosis is considered as a public health problem in Tunisia (affects about 17 Tunisian people /100,000 every year according to The National League against Tuberculosis and Lung Disease) and the increasing risks of toxicity with using high RIF doses in antistaphylococcal infections justify the necessity of RIF TDM.

Therefore, it was necessary to develop a sensitive, accurate and reproducible analytical method to analyse these samples. Numerous methods have been published previously for the analysis of RIF in biological fluids (plasma, serum, urine). The most common described procedures include microbiological assays (Bruzzese et al., 2000), HPLC, thermospray mass spectrometry and electrospray mass spectrometry (Korfmacher et al., 
1993); HPLC/tandem mass spectrometry method (Stefan et al., 2011; Lorena et al., 2010; Fang et al., 2010; De Velde et al., 2009; Song et al., 2007) and HPLC methods (Deirder et al., 2011; Marina et al., 2010; Allanson et al., 2007; Calleja et al., 2004; Hemanth et al., 2004; Moussa et al., 2002; Walubo et al., 1994; Weber et al., 1983). Most of them needed relatively large volume of samples $(\geq 0.5 \mathrm{~mL})$ (Conte et al., 2000; Walubo et al., 1994; El-Yazigi and Raines, 1992; Swart and Papgis, 1992; Jamaluddin et al., 1990; Ishii and Ogata, 1988; Woo et al., 1987; Chan, 1986; Ratti et al., 1981) and involve complex or very long extraction procedures, which notably increase the analysis time (Woo et al., 1987; Ratti et al., 1981). The present study was undertaken to develop and validate a simple and rapid HPLC method with UV detection, which could be useful for TDM of RIF in routine setting in patients as well as to evaluate pharmacokinetic of RIF.

\section{Materials and Methods}

Chemicals and reagents. Lyophilic Rifadine ${ }^{\circledR}$ was provided from Sanofi Aventis (Tunis, Tunisia). The internal standard (IS) clonazepam $\left(\right.$ Clonazepam ${ }^{\circledR}$ ) was provided by Pharmascience (Montreal, Canada). Rifamycin ${ }^{\circledR} 1000$ 000UI/100 (887 IU/mg) was provided by Thea (France).

Acetonitrile HPLC grade, Methanol HPLC grade, Water HPLC grade, $\mathrm{K}_{2} \mathrm{HPO}_{4}$ buffer HPLC grade and Diethylamine HPLC grade were obtained from Scharlau (Tunis, Tunisia). Orthophosphoric acid $\mathrm{H}_{3} \mathrm{PO}_{4}$ was provided by Prolabo (Tunis, Tunisia). Bidistilled water was prepared in the Laboratory of Clinical Pharmacology of the National Centre of Pharmacovigilance (Tunis, Tunisia).

Preparation of solutions. RIF solution SRF1 $(60 \mathrm{mg} / \mathrm{mL})$ was prepared from dilution of $600 \mathrm{mg}$ of lyophilic RIF powder dissolved in $10 \mathrm{~mL}$ of water for injection and stored at $-20{ }^{\circ} \mathrm{C}$ (for maximum 6 months). A RIF solution SRF2 $(600 \mu \mathrm{g} / \mathrm{mL})$ was prepared by diluting of SRF1 in the bidistilled water. Clonazepam solution $(125 \mu \mathrm{g} / \mathrm{mL})$ was prepared in methanol and stored at $-20{ }^{\circ} \mathrm{C}$ in dark.

Two plasmatic solutions of RIF PRF1 $(100 \mu \mathrm{g} / \mathrm{mL})$ and PRF2 $(12 \mu \mathrm{g} / \mathrm{mL})$ were prepared by diluting in free human plasma. These solutions were freshly prepared before each experiment. They were used for preparation of standards (STD) of RIF (1, 2, 3, 5, 6, 9, 10, 12, 20 and $40 \mu \mathrm{g} / \mathrm{mL}$ ) used for validation procedure by diluting in blank human plasma. Blank human plasma for analytical development and validation was obtained from Blood Bank (HUC Charles Nicolle, Tunisia).

HPLC equipment. The HPLC system manufactured by Varian ${ }^{\circledR}$ (Australia) was used for the present study. For the data acquisition and integration, Galaxie chromatography data system version 1.9.3.2 software operated by Pentium 4HT was used.

Chromatography conditions. RIF was separated using a LiChocart cartridge column $(150 \times 4.6 \mathrm{~mm})$ filled with Lichrospher $100 \mathrm{C} 18$, having a $5 \mu \mathrm{m}$ practical size (Merck, France) maintained at $25^{\circ} \mathrm{C}$. The samples were eluted in a mobile phase consisting of $0.05 \mathrm{M}$ dipotassic hydrogen phosphate buffer and acetonitrile $(53 / 47, \mathrm{~V} / \mathrm{V})$ with $0.086 \%$ diethylamin, $\mathrm{pH}=4.46$ at a flow rate of $0.6 \mathrm{~mL} / \mathrm{min}$. The mobile phase was filtered through a $0.22 \mu \mathrm{m}$ filter (Millipore) and degassed under vacuum prior to use. The detector wavelength was set at $340 \mathrm{~nm}$.

Sample extraction. Aliquots of $100 \mu \mathrm{L}$ plasma samples (blank, standard or patient sample) and $20 \mu \mathrm{L}$ of IS solution were vortexed for $1 \mathrm{~min}$. Methanol $200 \mu \mathrm{L}$ was added to the mixture, re-vortexed for $3 \mathrm{~min}$ and let stand for $10 \mathrm{~min}$ in dark. Each sample was centrifuged at $4{ }^{\circ} \mathrm{C}(4000 \mathrm{~g} \times 12 \mathrm{~min})$, and then $50 \mu \mathrm{L}$ of the supernatant was injected into the HPLC column for quantification.

Method validation. Validation study was performed according to two references; (a) US Food Drug Administration (US FDA, 2001) guidelines for bioanalytical methods for evaluation of precision, accuracy, recovery and linearity and (b) US Pharmacopoeia (USP, 1999) for the determination of limit of detection and limit of quantification.

Linearity. The calibration curves were prepared $(n=6)$ with seven increasing concentrations of RIF (STD; $\mu \mathrm{g} / \mathrm{mL})$. The final concentrations of RIF in plasma samples were $1,3,6,9,12,20$ and $40 \mu \mathrm{g} / \mathrm{mL}$. They were built with the peak areas ratios of each STD and IS, and fitted using linear regression.

Precision and accuracy. Replicate analysis $(\mathrm{n}=5)$ of STDs at the 4 concentrations (2, 5, 10 and $20 \mu \mathrm{g} / \mathrm{mL}$ ) was used for the precision and accuracy determination. All four concentrations were chosen to encompass the whole range of the calibration curve corresponding to the drug levels frequent in the majority of patients samples. Inter-assay accuracy and precision were determined by repeated analysis performed in three different 
days. The concentration in each sample was determined using calibration curve prepared on the same day. The precision was calculated as the coefficient of variation (CV \%) within a single run (intraday) and between different assays in different days (interdays). The analytical series were considered valid and accepted only if the percentage of deviation (bias) between theoretical and back-calculated (experimental) concentrations for each calibration level samples were less than $10 \%$.

Accuracy was measured as the percentage difference between measured value and nominal value, according the equation: Bias $(\%)=\left[\left(\mathrm{C}_{\text {measured }}-\mathrm{C}_{\text {theoretical }}\right) / \mathrm{C}_{\text {theoretical }}\right]$ $\times 100 \%$, where $\mathrm{C}_{\text {measured }}$ and $\mathrm{C}_{\text {theoretical }}$ are the determined (observed) concentration of RIF with the present method and their theoretical concentrations in the spiked plasma samples, respectively. Extractions were performed 3 times for each sample.

Determination of limit of detection and limit of quantification (LOQ). Limit of detection (LOD) was calculated using the equation $\mathrm{LOD}=3.3(\mathrm{SD} / \mathrm{b})$ and limit of quantification (LOQ) was calculated using the equation $\mathrm{LOQ}=10(\mathrm{SD} / \mathrm{b})$, where, $\mathrm{SD}$ is the standard deviation and $\mathrm{b}$ is the slope of the calibration curve (US pharmacopoeia).

The aim was to make the bias and CV \% less than $10 \%$ for all quality control standards except for the LOQ where less than $20 \%$ was accepted.

Statistical analysis. Validation data and the equation of the calibration curve were calculated by regression analysis using the software-package Pythagore Biostat (Version 2.0). Data were given as mean \pm SD.

Clinical application. The method was successfully applied to the monitoring of RIF in 28 blood samples provided from patients treated by RIF for tuberculosis or staphylococcal infection diseases. Samples were accompanied with patient's clinical information (age, body weight, sex, indication, RIF's dose).

Samples $(3 \mathrm{~mL})$ were collected in tubes containing anticoagulant (Li heparin) $2 \mathrm{~h}$ (time corresponding to maximum concentration) after taking RIF oral dose. Plasma was obtained after blood samples centrifugation at $1400 \mathrm{~g} \times 10 \mathrm{~min}$ at $4^{\circ} \mathrm{C}$ and stored until HPLC analysis at $-20{ }^{\circ} \mathrm{C}$.

\section{Results and Discussion}

Method development. An isocratic method was used. Different ratios, flow-rates, $\mathrm{pHs}$ of mobile phase and column temperatures were studied in order to shorten the retention time of RIF and to improve peak symmetry. However, the optimal assay conditions were found when using ratio of 53/47, V/V (buffer/ACN), and $0.086 \%$ of diethylamin. The $\mathrm{pH}$ was adjusted to 4.46 with orthophosphoric acid, the column temperature set at $25^{\circ} \mathrm{C}$ and the flow-rate at $0.6 \mathrm{~mL} / \mathrm{min}$. The peaks were well resolved with $\lambda$ max at $340 \mathrm{~nm}$. Retention time of RIF in these conditions was $5.2 \pm 0.05 \mathrm{~min}$.

The choice of the internal standard (IS) is a crucial step in the method development, as observed in this study to quantify RIF with an internal calibration technique. The internal standard must be added at the beginning of the extraction and should follow the drug in all stages of extraction.

It must be well separated from the peak of RIF, having a retention time close to the molecule and a total analysis time as short as possible. Several internal standards are described in the literature such as papaverine hydrochloride (Allanson et al., 2007), p-dimethyl (Chan, 1986), rifapentine (Panchagnula et al., 1999) and sulindac (Lau et al., 1996). Two molecules were tried in this study; Clonazepam $(5 \mu \mathrm{g} / \mathrm{mL})$ and Rifamycin $(11.27 \mu \mathrm{g} / \mathrm{mL})$ (derivative of Rifampicin) and these were detected at retention time of 6.46 and $5.47 \mathrm{~min}$, respectively. Rifamycin was ruled out because there were impurities accompanying the peak of Rifamycin and Clonazepam was kept as internal standard at the end of this step. The total time for each sample injection was about $10 \mathrm{~min}$. Retention times were approximately $5.2 \pm 0.05$ min for RIF and $6.3 \pm 0.05$ for IS for all assays.

Two extraction methods have been described for RIF in literature, a solid-liquid (Aparicio et al., 2006; Conte et al., 2000; Walubo et al., 1994; El-Yazigi and Raines, 1992; Swart and Papgis, 1992; Jamaluddin et al., 1990; Ishii and Ogata, 1988; Woo et al., 1987) and a liquidliquid (Lau et al., 1996; Chan, 1986). Several extraction solvents have been described; hydrochloric acid $0.1 \mathrm{M}$ (Lau et al., 1996), acetonitrile (Deirder et al., 2011; Marina et al., 2010; Allanson et al., 2007; Aparicio et al., 2006; Calleja et al., 2004, Hemanth et al., 2004; Conte et al., 2000; Walubo et al., 1994; El-Yazigi et al., 1992; Swart and Papgis, 1992; Jamaluddin et al., 1990; Ishii and Ogata, 1988; Woo et al., 1987; Ratti et al., 1981). A precipitation of plasmatic proteins was carried out in this study using methanol.

Validation. The specificity of the method was examined by comparing the chromatogram of the blank human 
plasma with that of the plasma spiked with RIF. Representative chromatogram of blank plasma extracted of RIF and representative chromatogram of RIF's standard plasma $(6 \mu \mathrm{g})$ and Clonazepam are shown in Fig. 1A-B. There were no interfering peaks in blank plasma at the retention time of RIF. No carry-over (memory effect) problem was observed in this assay as $50 \mu \mathrm{L}$ of mobile phase was injected into the HPLC system after analyzing plasma containing RIF.

Isoniazid, pyrazinamide and ethanbutol, which are often co-administered with RIF, did not interfere with the chromatograms.

Mean regression coefficient $\left(\mathrm{r}^{2}\right)$ of all RIF calibration curves was $0.9914 \pm 0.008(\mathrm{n}=6)$ (data not shown). So the method was linear in concentration range 1 to $40 \mu \mathrm{g} / \mathrm{mL}$.

The precision and accuracy of data obtained from controls have been presented in Table 1. Intra-day within day $\mathrm{CV} \%$ of the assay varied from $1.99 \%$ at $10 \mu \mathrm{g} / \mathrm{mL}$ to $8.86 \%$ at $2 \mu \mathrm{g} / \mathrm{mL}$. Intra-day accuracy of estimation in different standards samples was found to be $-16.30 \%$ for $2 \mu \mathrm{g} / \mathrm{mL},-7.04 \%$ for $5 \mu \mathrm{g} / \mathrm{mL}, 1.40 \%$ for $10 \mu \mathrm{g} / \mathrm{mL}$ and $-1.78 \%$ for $20 \mu \mathrm{g} / \mathrm{mL}$. Inter assay between day coefficient of variation was $2.78 \%$ for $20 \mu \mathrm{g} / \mathrm{mL}$ and $2.95 \%$ for $2 \mu \mathrm{g} / \mathrm{mL}$. The inter-day accuracy of estimation in the seeded samples varied from $-1.66 \%$ to $2.1 \%$ for
$20 \mu \mathrm{g} / \mathrm{mL}$ and $10 \mu \mathrm{g} / \mathrm{mL}$, respectively. These results suggest good precision and accuracy of the method.

The recovery of RIF was assessed by comparing the response of five replicates of extracted samples $(2,5$, 10 and $20 \mu \mathrm{g} / \mathrm{mL}$ ) to the response of pure standard at the same concentration level. The standard specimens were diluted in bidistilled water and injected directly

Table 1. Precision and accuracy of RIF in human plasma

\begin{tabular}{llll}
\hline \hline $\begin{array}{l}\text { Added RIF } \\
\text { concentration } \\
(\mu \mathrm{g} / \mathrm{mL})\end{array}$ & $\begin{array}{l}\text { Observed } \\
\text { RIF concentration } \\
(\text { Mean } \pm \mathrm{SD} ; \mu \mathrm{g} / \mathrm{mL})\end{array}$ & $\begin{array}{l}\text { Accuracy } \\
(\%)\end{array}$ & $\begin{array}{l}\text { Precision } \\
(\%)\end{array}$ \\
\hline $\begin{array}{l}\text { Intra-day* } \\
\text { Bias } \%\end{array}$ \\
2
\end{tabular}

${ }^{*} \mathrm{n}=5$ assays in the same day for each concentration; $* * \mathrm{n}=5$ assays per day during 3 days for each concentration. Daily (intra-day and day to day (inter-day) precisions are represented as mean values $\pm \mathrm{SD}$ of five different assays for each concentration.
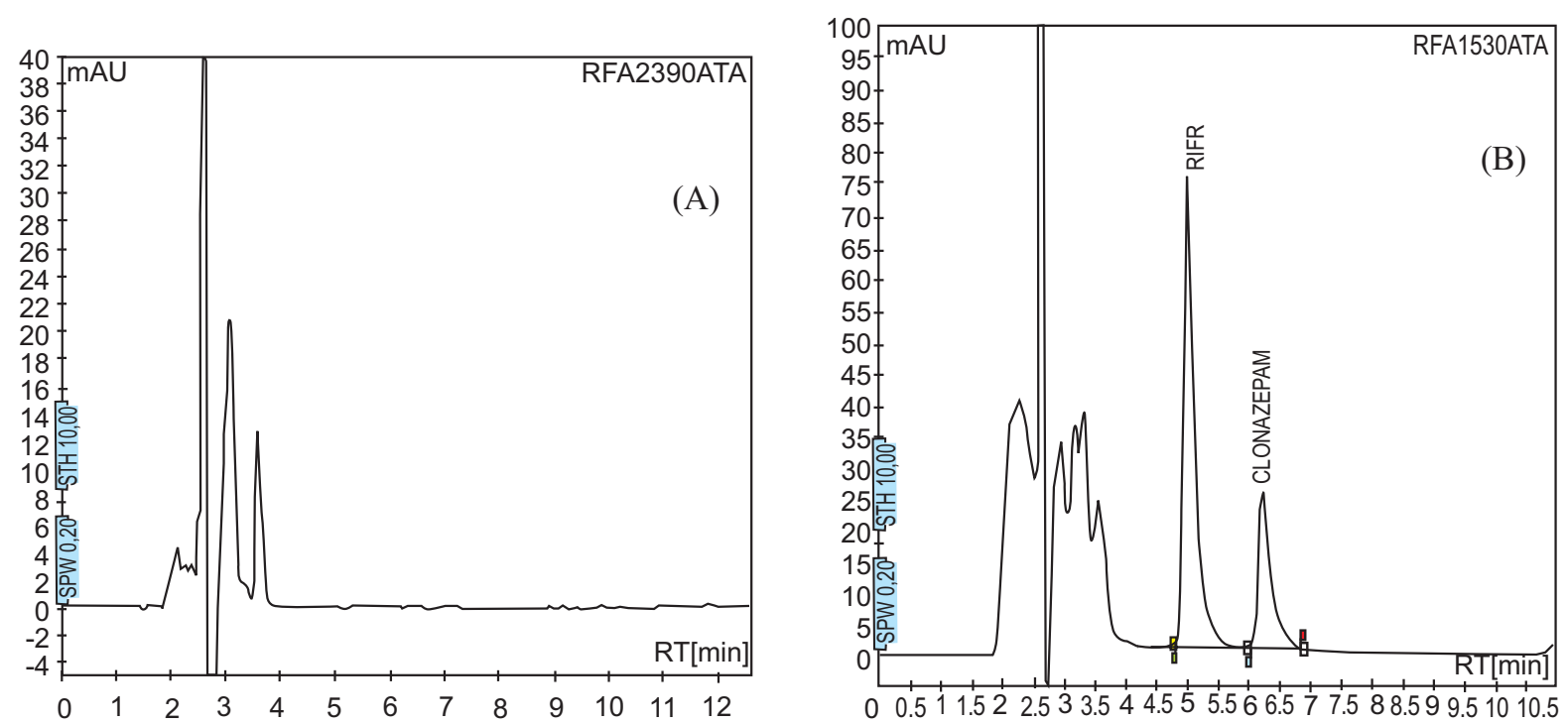

Fig. 1A-B. Representative chromatograms of blank and RIF spiked plasma (A) representative chromatogram of blank plasma extracted of RIF (B) representative chromatogram of RIF standard plasma (STD $6 \mu \mathrm{g} / \mathrm{mL}$ ) extracted. 
into the HPLC system. The recovery of RIF was greater than $90 \%$ (data not shown) for all tested concentrations.

The LOD and LOQ calculated were $0.208 \mu \mathrm{g} / \mathrm{mL}$ and $0.632 \mu \mathrm{g} / \mathrm{mL}$, respectively.

Application of the method. As shown by various chromatograms (chromatogram for the blank sample and chromatogram for $18.7 \mu \mathrm{g} / \mathrm{mL}$ of RIF in plasma from a patient treated for a staphylococcal infection) with $900 \mathrm{mg} /$ day of RIF (Fig. 2) the present HPLC/UV method seems sufficiently sensitive to be used for maximal concentration $\left(\mathrm{C}_{\max }\right)$ RIF's plasma level determination. Plasma monitoring of RIF was realized in 28 patients ( 28 samples). All samples were performed $2 \mathrm{~h}$ after taking $\mathrm{RIF}\left(\mathrm{C}_{\max }\right)$.

RIF was prescribed for tuberculosis in 17 patients whose average age was $36.7 \pm 15.5$ yrs and average weight was $73.4 \pm 18.47 \mathrm{~kg}$ and for staphylococcal infection in 11 patients whose average age was $59.88 \pm 19.4$ yrs and average weight was $67.83 \pm 9.21 \mathrm{~kg}$. RIF doses were varied from $5.36 \mathrm{mg} / \mathrm{kg} /$ day to $12.5 \mathrm{mg} / \mathrm{kg} /$ day, with a mean of $8.83 \mathrm{mg} / \mathrm{kg} /$ day for two indications. Founded concentrations varied from $1.97 \mu \mathrm{g} / \mathrm{mL}$ to $28 \mu \mathrm{g} / \mathrm{mL}$ with a mean of $9.81 \mu \mathrm{g} / \mathrm{mL}$. In literature target $\mathrm{C}_{\max }$ varied from $4 \mu \mathrm{g} / \mathrm{mL}$ to $24 \mu \mathrm{g} / \mathrm{mL}$ according to the germ, way of action and the dose. A target concentration of $8 \mu \mathrm{g} / \mathrm{mL}$ was desirable. In our population four concentrations were observed below $4 \mu \mathrm{g} / \mathrm{mL}$,

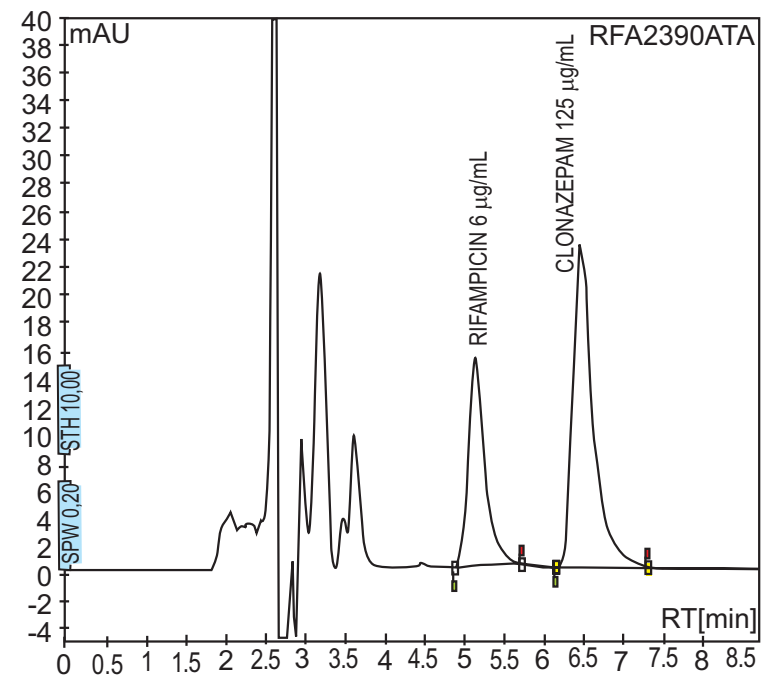

Fig. 2. Representative chromatograms for $T_{2 h}$ $10.2 \mu \mathrm{g} / \mathrm{mL}$ of RIF in plasma from a staphylococcal infection patient treated with $900 \mathrm{mg} /$ day of RIF.
12 concentrations between $4 \mu \mathrm{g} / \mathrm{mL}$ and $8 \mu \mathrm{g} / \mathrm{mL}$, and 11 concentrations were up to $8 \mu \mathrm{g} / \mathrm{mL}$.

\section{Conclusion}

A novel validated method for the quantification of RIF in human plasma was developed using HPLC with UV detection. The assay is accurate, precise and fast. This simple separation method uses isocratic mobile phase conditions making the assay accessible to any laboratory in institute.

\section{References}

Allanson, A.L., Cotton, M.M., Tettey, J.N.A., Boyter, A.C. 2007. Determination of rifampicin in human plasma and blood spots by high performance liquid chromatography with UV detection: A potential method for therapeutic drug monitoring. Journal of Pharmaceutical and Biomedical Analysis, 44: 963-969.

Aparicio, I., Bello, M.A., Callejon, M., Guiraum, A. 2006. Simultanious determination of rifampicin and sulbactam in mouse plasma by high-performance liquid chromatography. Biomedical Chromatography, 20: 748-752.

Baietto, L., D’Avolio, A., DeRosa, F.G., Garazzino, S., Michelazzo, M., Ventimiglia, G., Siccardi, M., Simiele, M., Sciandra, M., Diperri, G. 2010. Development and validation of a imultaneous extraction procedure for HPLC-MS quantification of daptomycin, amikacin, gentamicin, and Rifampicine in human plasma. Analytical and Bioanalytical Chemistry, 396: 791-798.

Bruzzese, T., Rimaroli, C., Bonabello, A., Mozzi, G., Ajay, S., Cooverj, N.D. 2000. Pharmacokinetics and tissue distribution of rifametane, a new 3 -azinomethyl-rifamycin derivative, in several animal species. Arzneimittelforschung, 50: 60-71.

Calleja, I., Maria, J., Blanco-Prieto, Noelia Ruz, Maria Jesus Renedo, Maria Carmen Dios - Vietrez. 2004. High-performance liquid-chromatographic determination of rifampicin in plasma and tissues. Journal of Chromatography A, 1031: 289-294.

Chan, K. 1986. Rifampicin concentrations in cerebrospinal fluid and plasma of the rabbit by high performance liquid chromatography. Methods and Findings in Experimental and Clinical Pharmacology, 8: 721-726.

Conte, J.E.Jr., Lin, E., Zurlinden, E. 2000. Liquid chromatographic determination of rifampicin in 
human plasma, bronchoalveolar lavage fluid, and alveolar cells. Journal of Chromatography Science, 38: 72-76.

DeVelde, F., Alffenaar, J.W., Wessels, A.M., Greijdanus, B., Uges, D.R. 2009. Simultaneous determination of clarithromycin, Rifampicin and their main metabolites in human plasma by liquid chromatographytandem mass spectrometry. Journal of Chromatography B, Analytical Technologies in the Biomedical and Life Sciences, 877: 1771-1777.

Deirder, F., Robert, O'C., Patrick, M., Gillian, Mc M. 2011. Simultaneous determination of efaverenz, Rifampicin and its metabolite desacetyl Rifampicin levels in human plasma. Journal of Pharmaceutical and Biomedical Analysis, 56: 785-791.

El-Yazigi, A., Raines, D.A. 1992. Simultaneous microdetermination of rifampin, deacetylrifampin, isoniazid, and acetylisoniazid in plasma by liquid chromatography with dual electrochemical and spectrophotometric detection. Pharmaceutical Research, 9: 812-816.

Fang, P.F., Cai, H.L., Li, H.D., Zhu, R.H., Tan, Q.Y., Gao, W., Xu, P., Liu, Y.P., Zhang, W.Y., Chen, Y.C. 2010. Simultaneous determination of isoniazid, Rifampicine, levofloxacin in mouse tissues and plasma by liquid chromatography-tandem mass spectrometry. Journal of chromatography B, Analytical Technologies in the Biomedical and Life Sciences, 878: 2286-2291.

Gallieni, M., Braidotti, P., Cozzolino, M., Romagnoli, S., Carpani, P. 1999. Acute tubulo-interstitial nephritis requiring dialysis associated with intermittent rifampicin use: case report. The International Journal of Artificial Organs, 22: 477-481.

Hemanth, K.A.K., Chandra, I., Geetha, R., Silambu, K., Lalitha, V., Prema, G. 2004. A validated highperformance liquid chromatography method for the determination of Rifampicin and desacetyl rifampicin in plasma and urine. Indian Journal of Pharmacology, 36: 231-233.

Ishii, M., Ogata, H. 1988. Determination of Rifampicin and its main metabolites in human plasma by highperformance liquid chromatography. Journal of Chromatography, 426: 412-416.

Jamaluddin, A.B., Sarwar, G., Rahim, M.A., Rahman, M.K. 1990. High-performance liquid chromatographic assay of Rifampicin in human serum. Journal of Chromatography, 525: 495-497.

Korfmacher, W.A., Bloom, J., Churchwell, M.I., Getek, T.A., Hansen, E.B.Jr., Holder, C.L.,
McManus, K.T. 1993. Characterization of three rifamycins via electrospray mass spectrometry and HPLC-thermospray mass spectrometry. Journal of Chromatography Science, 31: 498-501.

Lau, Y.Y., Hanson, G.D., Carel, B.J. 1996. Determination of Rifampin in human plasma by highperformance liquid chromatography with ultraviolet detection. Journal of Chromatography B, Biomedical Applications, 676: 147-152.

Maggi, N., Pasqualucci, C.R., Ballotta, R., Sensi, P. 1966. Rifampicin: a new orally active rifamycin. Chemotherapy, 11: 285-292.

Marina, S.B., Carlo, B., Mateus, M.B., Regina, H.C.Q., Wilson, R.M., Sonia, A.C.D, Lidervan, P.M., Maria, E.C.Q. 2010. Rifampicin determination in plasma by stir bar-sorptive extraction and liquid chromatography. Journal of Pharmaceutical and Biomedical Analysis, 51: 1078-1083.

Moussa, L.A., Khassouani, C.E., Soulaymani, R., Jana, M., Cassanas, G., Alric, R., Hüe, B. 2002. Therapeutic isoniazid monitoring using a simple high-performance liquid chromatographic method with ultraviolet detection. Journal of Chromatography B. Analytical and Technological Biomedical Life Science, 766: 181-187.

Panchagnula, R., Sood, A., Sharda, N., Kaur, K., Kaul, C.L. 1999. Determination of rifampicin and its main metabolite in plasma and urine in presence of pyrazinamide and isoniazid by HPLC method. Journal of Pharmaceutical and Biomedical Analysis, 18: 1013-1020.

Peloquin, C.A. 2002. Therapeutic drug monitoring in the treatment of turberculsis. Drugs, 62: 21692183.

Peloquin, C.A. 1997. Using therapeutic drug monitoring to dose the antimycobacterial drugs. Clinics in Chest Medicine, 18: 79-87.

Peloquin, C.A., Nitta, A.T., Burman, W.J., Brudney, K.F., Miranda-Massari, J.R., McGuiness, M.E., Gerena, G.T. 1996. Low antituberculosis drug concentrations in patients with AIDS. The Annals Pharmacotherapy, 30: 919-925.

Ratti, B., Parenti, R.R., Toselli, A., Zerilli, L.F. 1981. Quantitative assay of Rifampicin and its main metabolite 25-desacetyl-rifampicin in human plasma by reversed-phase high-performance liquid chromatography. Journal of Chromatography, 225: 526-531.

Song, S.H., Jun, S.H., Park, K.U., Yoon, Y., Lee, J.H., Kim, J.Q., Song, J. 2007. Simultaneous determina- 
tion of first-line and anti-tuberculosis drugs and their major metabolic ratios by liquid chromatography/tandem mass spectrometry. Rapid Communication in Mass Spectrometry, 21: 1331-1338.

Stefan, O., Jette, P., Monica, V., Werner, S. 2011. LCMS/MS method for the simultaneous determination of clarithromycin, rifampicin and their main metabolites in horse plasma, epithelial lining fluid and broncho-alveolar cells. Journal of Pharmaceutical and Biomedical Analysis, 55: 194-201.

Swart, K.J., Papgis, M. 1992. Automated high-performance liquid chromatographic method for the determination of rifampicin in plasma. Journal of Chromatography, 593: 21-24.

Tsankov, N., Angelova, I. 2003. Rifampin in dermatology. Clinics in Dermatology, 21: 50-55.

USFDA. 2001. Reviewer Guidance for Industry. Bioanalytical Methods Validation, Center for Drug Evaluation and Research, US Food and Drug Administration, USA.

USP. 1999. US Pharmacopeia 24, Validation of Compendia Methods, Section <1225>, 2149 pp., United States Pharmacopeal Convention, Rockville, MD, USA.
Walubo, A., Smith, P., Folb, P.I. 1994. Comprehensive assay for pyrazinamide, Rifampicin and isoniazid with its hydrazine metabolites in human plasma by column liquid chromatography. Journal of Chromatography B, Biomedical Applications, 658: 391-396.

Weber, A., Opheim, K.E., Smith, A.L., Wong, K. 1983. High-pressure liquid chromatographic quantification of rifampin and its two major metabolites in urine and serum. Review of Infectious Diseases, 5: S433-S439.

Woo, J., Wong, C.L., Teoh, R., Chan, K. 1987. Liquid chromatographic assay for the simultaneous determination of pyrazinamide and Rifampicin in serum samples from patients with tuberculous meningitis. Journal of Chromatography, 420: 73-80.

Yew, W.W. 1998. Therapeutic drug monitoring in antituberculosis chemotherapy. Therapeutic Drug Monitor, 20: 469-472.

Zent, C., Smith, P. 1995. Study of the effect of concomitant food on the bioavailability of RIF, isoniazid and pyrazinamide. Tuberculosis Lung Diseases, 76: 109-113. 